\title{
Cognitive Impairment in Alzheimer's Disease: Longitudinal Data from Brazilian Elderly
}

\author{
Daniel Bartholomeu', Juliana Francisca Cecato², José Eduardo Martinelli², \\ José Maria Montiel' \\ ${ }^{1}$ FIEO University Center, Osasco, Brazil \\ 2Jundiaí Medical School, São Paulo, Brazil \\ Email: d bartholomeu@yahoo.com.br
}

Received 10 April 2014; revised 9 May 2014; accepted 23 May 2014

Copyright (C) 2014 by authors and Scientific Research Publishing Inc.

This work is licensed under the Creative Commons Attribution International License (CC BY). http://creativecommons.org/licenses/by/4.0/

(c) (i) Open Access

\begin{abstract}
Research on cognitive aging is becoming increasingly common because aging is a global phenomenon and brings with it many challenges, for example, the increased incidence of dementias such as Alzheimer's Disease (AD). Even if the cognitive decline in AD is apparently linear, impairment of autonomy in activities of daily living does not follow the same pattern. Objectives: To monitor and evaluate the cognitive aspects of elderly diagnosed with Alzheimer's disease. Methodological procedures: This research was conducted from January 2006 to July 2013 at the Clinic of Geriatrics and Gerontology. Longitudinal study of 51 elderly patients aged 60 years, of both sexes who received a diagnosis of Alzheimer's disease by DSM-IV (APA, 1994) and NINDS-ADRDA (McKhann et al., 2011). Results: From the results obtained in the present study, we observed that the participants had a decline in cognitive function from the first to the second assessment, even with drug treatment.
\end{abstract}

\section{Keywords}

Alzheimer Disease, Neuropsychiatric Evaluation, Cognition, Learning

\section{Introduction}

In recent years, the amount of studies and research on cognitive aging has increased significantly. Concerns have arisen in various directions in relation to this phenomenon, since life expectancy is increasing and people expect to live better than before [1]. The increase in life expectancy led to a higher prevalence of neurodegener- 
ative diseases such as dementia. The Alzheimer's disease (AD) has been studied because it's a type of dementia that occurs most frequently. As spoken by Frota et al. [2], the clinical criteria for the diagnosis of AD are, among other factors, the decline of the following areas: language (recollections of words), visuospatial (spatial cognition, agnosia for objects or faces, simultaneoagnosia and alexia), and executive functions (change in thinking, judgment and problem solving). Even the cognitive decline in $\mathrm{AD}$ is apparently linear, the impairment of autonomy in activities of daily living does not follow the same pattern. Therefore, it is important to understand the characteristics that influence the changes from the disease [3].

$\mathrm{AD}$ causes deterioration in functional capacity, making it difficult for the individual to perform activities of daily living, which will depend on an assistant [4]. Thus, functional capacity has been one of the major important health concerns of the elderly people and it is considered essential in assessing the population health, especially those with dementia, such as AD. Research has shown that changes in the performance of life daily activities (ADL) can occur from the early stages of the disease [5]. In a longitudinal study, 107 patients with AD were assessed at baseline, after six months and after 12 months in order to check the cognitive and functional decline. The results indicated that patients showed no deficits in basic activities of daily living even with severe cognitive impairment. Furthermore, the instrumental activities of daily living, which are more complex, were affected in the initial stage of the disease [6].

The choice of neuropsychological tests to assess cognitive function may vary according to the age and educational time because scholarity has a very important participation in the evaluation, since it influences the cognitive performance as a matter of debate and research constant [7] (Moreira et al., 2009). So, it is important to follow the evolution of cognitive impairment patients to propose possible interventions, considering the demands and potential health and life of the elderly people. It is also important to determine which tools will be applied in patients with $\mathrm{AD}$, since according to the educational level of the patient, it is recommended the use of certain tests. Low scholarity can decrease the sensitivity of the instruments used [8]. The objectives are to monitor and evaluate the cognitive aspects of elderly diagnosed with Alzheimer's disease.

\section{Methodological Procedures}

This research was conducted from January 2006 to July 2013 at the Clinic of Geriatrics and Gerontology in São Paulo/Brazil. Longitudinal study of 51 elderly patients aged 60 years, of both sexes who received a diagnosis of Alzheimer's disease by DSM-IV [9] and NINCDS-ADRDA [10]. Patients received a detailed clinical history, laboratory tests and neuroimaging to exclude the non-Alzheimer dementia type. Patients also received a neuropsychiatric assessment, like: the Cambridge Cognitive Examination [11], the screening of the Mini-Mental State Examination (MMSE) [12], the Verbal Fluency test (FV) version animals, fruits and words with the letter "M" [13], the Clock Drawing Test (CDT) scales by Mendez et al. [14] and Shulman et al. [15]. Activities of daily living were assessed by the Questionnaires Pfeffer Functional Activities (QAFP) [16]. Depressive symptoms were assessed using the Geriatric Depression Scale (GDS) with 15 items [17].

Patients under 59 years, with a history of cerebrovascular accident (CVA), Parkinsonism, severe dementia (Clinical Dementia Rating $\geq 3$ ), dementia of non-Alzheimer type, visual impairment and that compromised motor performance on cognitive tests, which passed through nonpharmacological treatment (cognitive rehabilitation) and those that did not accept to participate were not included as exclusion criteria. The participants made the first assessment and were reassessed at most two years after the first neuropsychiatric evaluation. After diagnosis, patients received drug treatment (rivastigmine, galantamine or donepezil) and none of them, until the time of the second assessment, was not taking memantine. It is important to enphasize that the treatment of these patients was exclusively drug. None of them had cognitive rehabilitation treatment.

\section{Statistical Analysis}

To analyze the patients' performance on cognitive tests in the first and second evaluation we used the SPSS (15.0). The descriptive analyzes regarding age, gender and education was realized considering, minimum, maximum and standard deviation. For the comparative analysis between categorical variables (CAMCOG, MMSE, TDR, and QAFP FV), first and second evaluation, we used the Wilcoxon test, testing the hypothesis unilateral, where $\mathrm{H} 0>\mathrm{H} 1$. 


\section{Results}

It can be observed that the average age of the group was 76.37 years (minimum $=60$, maximum $=93$, standard deviation $[\mathrm{SD}]=6.35)$. Regarding gender, $37(72.5 \%)$ were female and $14(27.5 \%)$ were male. Regarding education, there was $5.9 \%$ (3) illiterate, $56.9 \%$ (29) between 1 - 4 years of schooling, 11.8\% (6) between 5 - 8 years and $25.5 \%$ (13) with over 9 years of study. Regarding the cognitive tests, Table 1 shows that the second evaluation was worse compared to the first assessment, suggesting an evolution of the disease even with drug treatment. According to the comparative analysis (Table 2) there are negative and statistically values for the evaluation of the CAMCOG $(Z=-5.608, p<0.0001)$, MMSE $(Z=-5.872, p<0.0001)$; FV animals $(Z=-3.238$, $p=$ $0.001)$, fruit $F V(Z=-2.356, p=0.018)$, and words with the letter " $M$ " $(Z=-2.667, p=0.008)$ and the clock drawing test Shulman the range of $(Z=-2.266, p=0.023)$ based on positive category. The variable that evaluates the functional activities (QAFP) also showed negative and statistically values ( $Z=-4.073, p<0.0001$ ), which was based on negative categories. But the clock drawing test for scale Mendez showed no statistically significant differences $(Z=-1.482, p=0.138)$. It can be inferred that the results in the second evaluation showed no differences on the average compared to the first evaluation.

\section{Discussion}

From the results obtained in the present study, we observed that the participants had a decline in cognitive function from the first to the second assessment, even with drug treatment. The disease causes a natural decline of the patient cognitive functions, but there are still some factors that can influence it, as the scholarity of each patient. Intellectual and linguistic difficulties when child, low scholarity and lower intellectual occupancy lifelong increases the risk to develop the AD [18]. A study by SABE (Health, Wellness and Aging), evaluated 2143 elderly residents in São Paulo’s city [19]. This group had, on average, 69 years old, with a predominance of women

Table 1. Values of tests CAMCOG, MMSE, verbal fluency, animals, fruits and words with the letter "M", TDR Shulman and Mendez scales and QAFP in pre and post assessment with maximum interval of two years. Med = mean, $\mathrm{SD}=$ standard deviation.

\begin{tabular}{ccc}
\hline Tests & $\mathbf{1}^{\text {a }}$ Evaluation Average (dp) & $\mathbf{2}^{\mathbf{a}}$ Evaluation Average (dp) \\
\hline CAMCOG & $78.73(14.18)$ & $69.59(14.50)$ \\
MEEM & $24.53(3.66)$ & $21.22(3.82)$ \\
FV animals & $11.31(3.69)$ & $9.73(3.33)$ \\
FV fruits & $9.86(2.67)$ & $8.73(2.68)$ \\
FV “M” & $8.75(3.87)$ & $7.18(3.70)$ \\
Mendez & $16.14(4.65)$ & $15.36(5.12)$ \\
Shulman & $3.67(0.92)$ & $3.32(1.12)$ \\
QAFP & $9.11(7.38)$ & $16.16(9.57)$ \\
\hline
\end{tabular}

Table 2. Comparative analysis by Wilcoxon test, testing the hypothesis $\mathrm{H}_{0}>\mathrm{H}_{1}$.

\begin{tabular}{ccc}
\hline hypothesis $\mathbf{H}_{\mathbf{0}}>\mathbf{H}_{\mathbf{1}}$ & $\mathbf{Z}$ & $\mathbf{p}$ \\
\hline CAMCOG 2-CAMCOG 1 & -5.608 (a) & $\mathbf{0 . 0 0 1}$ \\
MEEM 2-MEEM 1 & -5.872 (a) & $\mathbf{0 . 0 0 1}$ \\
FV animals 2-FV animals 1 & -3.238 (a) & $\mathbf{0 . 0 0 1}$ \\
FV fruits 2-FV fruits 1 & -2.356 (a) & $\mathbf{0 . 0 1 8}$ \\
FV “M” 2-FV “M” 1 & -2.667 (a) & $\mathbf{0 . 0 0 8}$ \\
Mendez 2-Mendez 1 & -1.482 (a) & 0.138 \\
Shulman 2-Shulman 1 & -2.266 (a) & $\mathbf{0 . 0 2 3}$ \\
QAFP 2-QAFP 1 & -4.073 (b) & $\mathbf{0 . 0 0 0 1}$ \\
\hline
\end{tabular}

${ }^{\mathrm{a} B}$ Based on positive ranks; ${ }^{\mathrm{b}}$ Based on negative ranks. 
(60\%). Among the participants, $60 \%$ had less than seven years of schooling. The cognitive decline, observed in $11 \%$ of the sample, was more frequent in the elderly who have never attended school (17\%) than in the elderly with more than seven years of scholarity, of which only $1 \%$ had difficulties [19].

It's written in the literature a strong association between the scholarity years and cognitive performance in cognitive tasks such as verbal fluency [20]. The high scholarity has been associated with several protective factors for dementia, such as: better performance on cognitive tasks, reduced cognitive decline and lower dementia incidence. These factors indicate the presence of cognitive reserve [21] [22]. The cognitive reserve is being analyzed in recent years and is usually assessed considering scholarity, socioeconomic status, occupations that the person has or had during life, leisure activities, IQ (intelligence quotient) and the level of literacy [23].

In a research realized, 174 patients with AD were subdivided and subjected to analysis according to their previous occupation and level of scholarity achieved. The results showed that participants in the group with less schooling and professional areas considered less complex compared to the intellectual demand performed worse when compared with more educated, favoring the concept of cognitive reserve [24]. Another interesting point of this study is that only the Clock Drawing Test, due the Mendez scale et al. [14] showed no significant difference in pre and post test participants. Although there are few studies in order to compare the test in individuals with low education using cognitive screening batteries to exclude the possibility of dementia in this population [25].

Observing the cognitive decline obtained with drug treatment, is also important the treatment with non-pharmacological, for example, with the cognitive training in an attempt to slow the process of cognitive loss. Studies have reported the efficacy of treatment with cognitive training, from the use of memory strategies and external compensatory strategies to assist the patients daily lives with AD, associated with drug therapy [26]. It is also notorious that all participants in this research adhered to the drug treatment with rivastigmine, galantamine or donepezil. None of the participants used Memantine in the treatment.

\section{Conclusion}

Alzheimer's disease is the dementia that affects more seniors today. Considering this fact, it is important to continue the studies and research that have the interest to evaluate the evolution of the disease and the different types of treatment for different groups of patients with AD. It is suggested that further researches can be made with a larger number of participants, with a longer time period, using other assessment tools and associating non-pharmacological treatment to try to obtain more important information about this disease.

\section{References}

[1] Camarano, A.A. (2002) Envelhecimento da população brasileira: Uma contribuição demográfica. In: Freitas, E.V., Py, L., Neri, A.L., Cançado, F.A.X., Gorzoni, M.L. and Rocha, S.M., Eds., Organizadores. Tratado de Geriatria e Gerontologia, Guanabara Koogan, Rio de Janeiro, 58-71.

[2] Frota, N.A.F., Nitrini, R., Damasceno, B.P., Forlenza, O.V., Dias-Tosta, E., Da Silva, A.B., et al. (2011) Criteria for the Diagnosis of Alzheimer's Disease: Recommendations of the Scientific Departamento of Cognitive Neurology and Aging of the Brazilian Academy of Neurology. Dementia e Neuropsychologia, 5, 146-152.

[3] Zidan, M., Arcoverde, C., Araújo, N.B., Vasques, P., Rios, A., Laks, J., et al. (2012) Motor and Functional Changes in Different Stages of Alzheimer's Disease. Revista de Psiquiatria Clínica, 39, 161-165.

[4] Luzardo, A.R. and Waldman, B.F. (2004) Atenção ao familiar cuidador do idoso com Doença de Alzheimer. Acta Scientiarum. Health Sciences, 26,135-145.

[5] Niegovan, V., Hing, M.M., Mitchell, S.L. and Molnar, F.J. (2001) The Hierarchy of Functional Loss Associated with Cognitive Decline in Older Persons. The Journals of Gerontology Series A: Biological Sciences, 56, 638-643. http://dx.doi.org/10.1093/gerona/56.10.M638

[6] Suh, S.W., Jensen, K.B., Jensen, M.S., et al. (2000) Histochemically-Reactive Zinc in Amyloid Plaques, Angiopathy, and Degenerating Neurons of Alzheimer's Diseased Brains. Brain Research, 852, 74-278. http://dx.doi.org/10.1016/S0006-8993(99)02096-X

[7] Moreira, P.I., Santos, M.I. and Oliveira, C.R. (2007) Alzheimer’s Disease: A Lesson from Mitochondrial Dysfunction. Antioxidants \& Redox Signaling, 9, 1621-1630.

[8] Ainslie, N. and Murden, R. (1993) Effect of Education on the Clock Drawing Dementia Screen in Nom-Demented Elderly Persons. Journal of American Geriatrics Society, 41, 249-252.

[9] American Psychiatry Association (1994) Diagnostic and Statistical Manual of Mental Disorders. 4th Edition, Wash- 
ington DC.

[10] Mckhann, G.M., Knopman, D.S., Chertkow, H., et al. (2011) The Diagnosis of Dementia Due to Alzheimer’s Disease: Recommendations from the National Institute on Aging-Alzheimer's Association Workgroups on Diagnostic Guidelines for Alzheimer's Disease. Alzheimers Dement, 7, 263-269. http://dx.doi.org/10.1016/j.jalz.2011.03.005

[11] Roth, M., Tym, E., Mountjoy, C.Q., Huppert, F.A., et al. (1986) CAMDEX. A Standardised Instrument for the Diagnosis of Mental Disorder in the Elderly with Special Reference to the Early Detection of Dementia. British Journal of Psychiatry, 149, 698-709. http://dx.doi.org/10.1192/bjp.149.6.698

[12] Folstein, M.F., Folstein, S.E. and Mchugh, P.R. (1975) Mini-Mental State: A Practical Method for Grading the Cognitive State of Patients for the Clinician. Journal of Psychiatric Research, 12, 189-198. http://dx.doi.org/10.1016/0022-3956(75)90026-6

[13] Brucki, S.M.D., Nitrini, R., Caramelli, P., Bertolucci, P.H.F. and Kamoto, I. (2003) Sugestões para o Uso do MiniExame do Estado Mental no Brasil. Arquivos de Neuro-Psiquiatria, 61, 777-781. http://dx.doi.org/10.1590/S0004-282X2003000500014

[14] Mendez, M.F., Ala, T. and Underwood, K. (1992) Development of Scoring Criteria for the Clock Drawing Task in Alzheimer's Disease. Journal of the American Geriatrics Society, 40, 1095-1099.

[15] Shulman, K.I., Gold, D.P., Cohen, C.A. and Zucchero, C.A. (1993) Clock-Drawing and Dementia in the Community: A Longitudinal Study. International Journal of Geriatric Psychiatry, 8, 487-496. http://dx.doi.org/10.1002/gps.930080606

[16] Pfeffer, R.I., Kurosaki, T.T., Harrah, C.H., Chance, J.M., et al. (1982) Measurement of Functional Activities in Older Adults in the Community. Journal of Gerontology, 37, 323-329. http://dx.doi.org/10.1093/geronj/37.3.323

[17] Yesavage, J.A., Brink, T.L., Rose, T.L., Lum, O., et al. (1983) Development and Validation of a Geriatric Depression Screening Scale: A Preliminary Report. Journal of Psychiatric Research, 17, 37-49. http://dx.doi.org/10.1016/0022-3956(82)90033-4

[18] Anttila, T., Helkala, E.L., Kivipelto, M., Hallikainen, M., Alhainen, K. and Heinonen, H. (2002) Midlife Income, Occupation, APOE Status, and Dementia: A Populationbased Study. Neurology, 59, 887-893. http://dx.doi.org/10.1212/WNL.59.6.887

[19] Lebrão, M.L. and Oliveira, Y.A. (2003) O Projeto Sabe (Saúde, Bem-Estar e Envelhecimento) No Município de São Paulo. USP, São Paulo.

[20] Kempler, D., Teng, E.L., Dick, M., Taussig, I.M. and Davis, D.S. (1998) The Effects of Age, Education, and Ethnicity on Verbal Fluency. Journal of the International Neuropsychological Society, 4, 531-538. http://dx.doi.org/10.1017/S1355617798466013

[21] Ardila, A., Ostrosky-Sollis, F., Rosselli, M. and Gomez, C. (2000) Age-Related Cognitive Decline during Normal Aging: The Complex Effect of Education. Archives of Clinical Neuropsychology, 15, 495-513.

[22] Habib, R., Nyberg, L. and Nilsson, L. (2007) Cognitive and Non-Cognitive Factors Contributing to the Longitudinal Identification of Successful Older Adults in the Betula Study. Neuropsychology, Development, and Cognition. Section B, Aging, Neuropsychology and Cognition, 14, 257-273. http://dx.doi.org/10.1080/13825580600582412

[23] Akbaraly, T.N., Singh-Manoux, A., Marmot, M. and Brunner, E.J. (2009) Education Attenuates the Association between Dietary Patterns and Cognition. Dementia Geriatric Cognitive Disorders, 27, 147-154. http://dx.doi.org/10.1159/000199235

[24] Wajman, J.R. and Bertolucci, P.H.F. (2010) Intellectual Demand and Formal Education as Cognitive Protection Factors in Alzheimer's Disease. Dementia e Neuropsychologia, 4, 320-324.

[25] Aprahamian, I., Martinelli, J.E. and Yassuda, M.S. (2008) Doença de Alzheimer em idosos com baixa escolaridade: O teste do Desenho do Relógio pode ser útil no rastreio cognitivo? Revista da Sociedade Brasileira de Medicina, 6, 130134.

[26] Fernández-Calvo, B., Rodríguez-Pérez, R., Contador, I., Rubio-Santorum, A. and Ramos, F. (2011) Eficacia del entrenamiento cognitivo basado en nuevas tecnologias en pacientes con demencia tipo Alzheimer. Psicothema, 23, 44-50. 